\title{
CONVENTIONS USED
}

\section{McCune-Reischauer System of Romanization}

Not all Korean letters (ban'gŭl) have clear and direct equivalents when transliterated into the roman alphabet, and thus Koreans commonly romanize their names to their own personal taste. For example, a single Korean name, $\mathrm{Yi}$, may be spelled Lee, $\mathrm{Li}$, Rhee, $\mathrm{Rhi}$, Nee, or Ni. This book follows the McCune-Reischauer (M-R) system for all Korean words except those personal names where individuals have already chosen their own spelling. In this case, the M-R spelling comes first, followed by the personal spelling in brackets; for example, Hong Ŭlsu [Hong Eul Soo].

\section{Pronunciation}

vowels as follows:

$a$ as in father

ŏ as the $\mathrm{u}$ in but

e as in egg

$\breve{\mathrm{u}}$ as the $\mathrm{e}$ in taken or spoken $i$ as in India ae like the a in apple

$o$ as in Ohio

oe like the ö in German

$u$ as in rule

consonants:

$$
\begin{array}{llll}
\mathrm{ch}=\mathrm{j} & \mathrm{t}=\mathrm{d} & \mathrm{t}^{\prime}=\mathrm{t} & \mathrm{ch}^{\prime}=\mathrm{ch} \\
\mathrm{p}=\mathrm{b} & \mathrm{k}=\mathrm{g} & \mathrm{k}^{\prime}=\mathrm{k} & \mathrm{p}^{\prime}=\mathrm{p}
\end{array}
$$

\section{Listing of Interviewees}

Last name, first name [personal choice of spelling if there is one],

(m) or (f) for male or female, birth date, job, province of birth.

Four interviewees chose to remain anonymous and are listed simply as last name, first initial [anonymous], (m) or (f), job.

Parentheses are used for interpolated translations;

for example, village school (sŏdang)

Brackets are used for explanatory material inserted by the author into an interview. 



\section{Under the Black Umbrella}




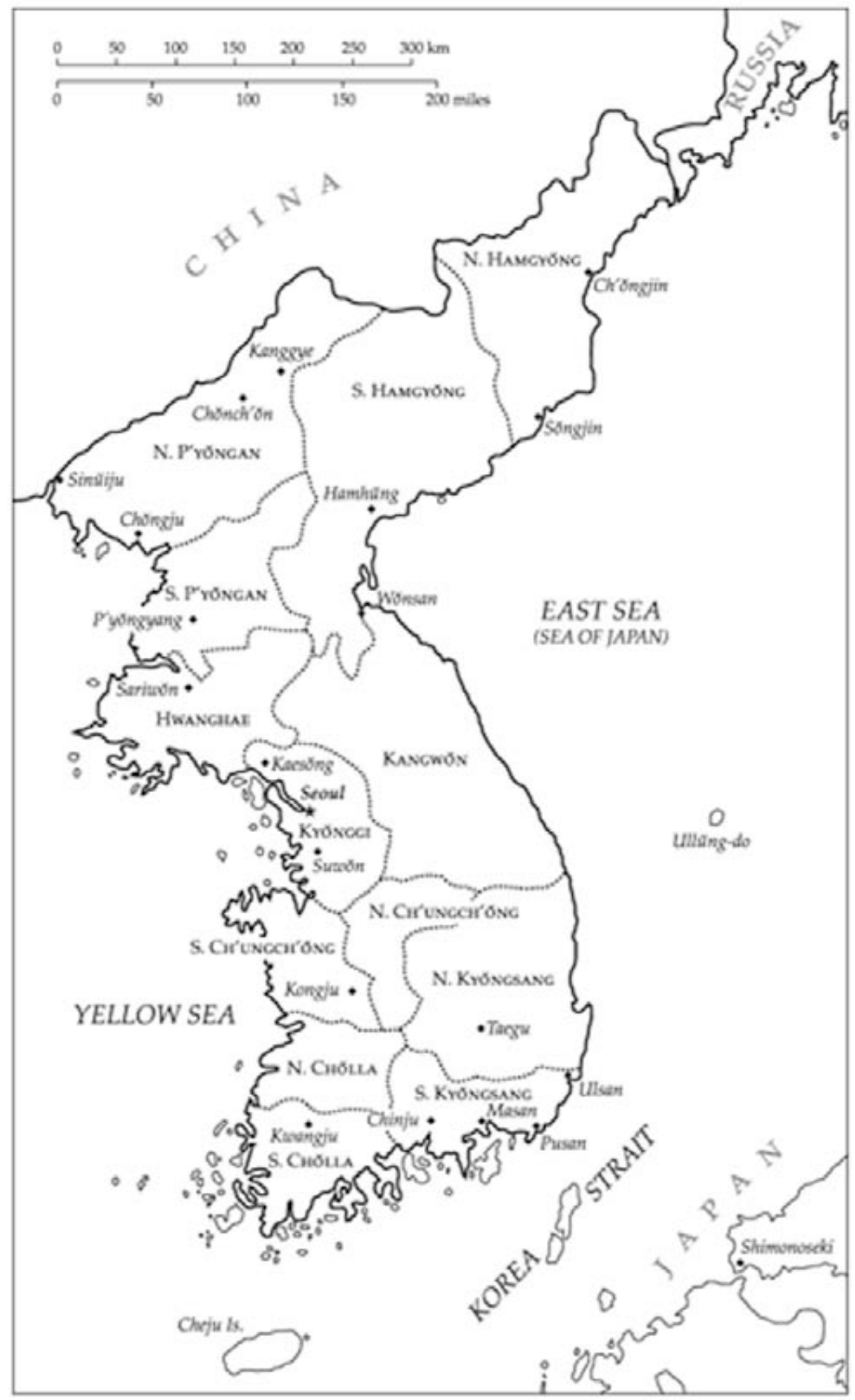

